\title{
El banquete macabro: la risa antropofágica en la Gran conquista de Ultramar
}

\section{The macabre banquet: anthropophagic laughter in the Gran Conquista de Ultramar}

\author{
María Eugenia Alcatena \\ maeualcatena@gmail.com \\ Seminario de Edición y Crítica Textual. Instituto \\ de Investigaciones Bibliográficas y Crítica Textual. \\ Universidad de Buenos Aires / CONICET, Argentina
}

Recepción: 30 Octubre 2020

Aprobación: 24 Abril 2021

Publicación: 03 Mayo 2021

Cita sugerida: Alcatena, M. E. (2021). El banquete macabro: la risa antropofágica en la Gran conquista de Ultramar. Olivar, 21(33), e093. https://doi.org/10.24215/18524478e093
Resumen: El artículo se propone analizar la forma en que en la Gran conquista de Ultramar se elabora el relato de los actos antropofágicos atribuidos a los cristianos en el marco de las cruzadas. Con este propósito se considera la tradición textual previa de la que abreva la crónica, para luego examinar las particularidades del episodio en su versión castellana, donde el hecho adquiere la forma de un banquete festivo y gozoso celebrado por los tahúres, los más pobres entre los cruzados. Se destaca especialmente, como el rasgo más notable del relato, el humor macabro que impregna la narración. Este análisis permite poner de relieve el modo en que un texto complejo, como la $G C U$, articula historia y procedimientos ficcionales en su representación de hechos del pasado, lo que la sitúa en una posición intermedia y crucial en el proceso de emergencia y primer desarrollo de la prosa de ficción en lengua vernácula.

Palabras clave: Antropofagia, Humor, Cruzadas, Tahúres, Ficcionalización.

Abstract: The aim of this paper is to analyse the way in which the Gran Conquista de Ultramar deals with the narration of the anthropophagic acts attributed to Christians during the Crusades. To this purpose, the textual tradition from which the chronicle draws its materials is briefly considered, and then we proceed to examine the particularities of the episode in the Castilian version, where the event is presented as a festive and joyous banquet celebrated by the Tafurs, the poorest among the crusaders. The macabre humour that pervades the episode stands out as its most notable feature, but not the only noteworthy one. The analysis makes it possible to highlight how a complex text, such as the $G C U$, articulates history and fictional procedures in its representation of past events, allowing us to place it in an intermediate and crucial position in the process of the emergence and early development of fictional prose in vernacular language.

Keywords: Anthropophagy, Humour, Crusades, Tafurs, Fictionalization. 


\section{LAS CRUZADAS COMO PEREgRINACIÓN Y LOS PADECIMIENTOS DEL CAMINO}

La Primera Cruzada significó un fenómeno sin precedentes en el occidente medieval, en el que se fusionaron los conceptos de la guerra santa y la peregrinación. ${ }^{1}$ Desde el Concilio de Clermont en adelante, la predicación de la cruzada aunó el llamamiento a emprender una expedición militar grandiosa, especialmente orientado a la caballería europea, su idiosincrasia y sus ambiciones, y el imaginario de la romería, el viaje a lugares sagrados realizado con fines devocionales o penitentes, con resonancia en la sensibilidad colectiva más vasta. Los cruzados eran instados a verse como peregrinos, embarcados en una aventura cuyo fin último era la purificación, la purga, la limpieza: en primer lugar, de la Tierra Santa, a través de la expulsión de los musulmanes que la tenían bajo su poder; pero también, y no menos importante, de sí mismos y de la cristiandad en su conjunto, corrompida por los pecados y desgarrada por los conflictos internos. Urbano II alentó esta concepción al conceder la indulgencia plenaria (y, por ende, la salvación del alma) como recompensa para quienes participaran de este peregrinaje tan singular.

A medida que los cruzados se adentraron en las tierras de Ultramar debieron afrontar obstáculos diversos. A los enfrentamientos militares con los musulmanes y, eventualmente, las pugnas entre líderes cristianos, se sumaron otras dificultades materiales, como el calor y la aridez del desierto, la falta de provisiones, la sed, la hambruna, la peste, la corrupción del aire por la acumulación de cadáveres y la mortandad resultante de la combinación de todos estos factores.

La Gran conquista de Ultramar (en adelante, $G C U$ ), la extensa crónica castellana de fines del siglo XIII sobre los hechos concernientes a las cruzadas, da cuenta de manera bastante pormenorizada de estos percances. Un episodio se destaca como la cima dramática de estas dificultades ligadas a los padecimientos del cuerpo arrojado a un entorno hostil: un grupo de cristianos, acuciados por los apremios de un sitio prolongado, la sucesión de batallas, las inclemencias del tiempo, la carestía de víveres, el hambre y las enfermedades, recurre a la antropofagia para asegurarse la supervivencia.

En la $G C U$, el episodio se recoge dentro del capítulo LX del Libro Segundo, de acuerdo con la segmentación del impreso de Salamanca de 1503 (Cooper, ed., 1979, II, pp. 35-51). ${ }^{2}$ En líneas generales, el relato es como sigue. Durante el sitio de Antioquía, la hambruna, la peste y la mortandad asolan al ejército cristiano, y en particular a los más pobres entre ellos, la gente menuda que ya ni siquiera encuentra hierbas silvestres con las que alimentarse. Proliferan las deserciones y el temor ante las amenazas de sublevación y desorden: "los hombres honrrados havían muy gran miedo de la gente menuda, que se levantasse contra ellos e los matassen, o se oviessen de meter en la villa para tornarse moros" (I, p. 542). En este marco, los tahúres -los más miserables entre los cruzados - le reclaman a su caudillo que les consiga algo de comer, o de lo contrario lo matarían y devorarían. El rey de los tahúres (el título informal por el que se conoce a ese caudillo ungido de manera espontánea por sus seguidores) se dirige entonces a la tienda de Pedro el Ermitaño, uno de los clérigos destacados de la expedición con especial predicamento entre los pobres, y le ruega que le entregue su asno para poder alimentar a los hombres. El clérigo no está dispuesto a ceder su montura, ya que de hacerlo quedaría impedido de desplazarse debido a la gota que lo aflige; responde entonces "que les mostraría asaz que comiessen, en manera que harían su provecho e muy gran pesar a sus enemigos” (II, p. 38). Ante esta respuesta, los tahúres se alegran.

E él, como era gran clérigo, començóles a fazer su sermón de cómo nuestro Señor mandara en la nueva ley, por el su apóstol san Pablo, que todas las cosas que hallassen quando menester les fuesse, que las santiguassen e las comiessen; e ellos, que hallarían allí mucha carne de aquellos moros que matavan, que podrían comer, que era mucho más sana que la de los asnos. E tanto les dixo por este lugar, que ellos fueron ende muy ledos. (II, p. 38)

Persuadidos, los tahúres descabezan, desuellan y desmiembran los cadáveres musulmanes desperdigados en el campo de batalla y los devoran, asados, cocidos o adobados con diferentes salsas para que sepan mejor, a lo largo de los días siguientes. Tanto gusto le toman a esta carne que, luego de acabar con los cadáveres 
insepultos, acuden a las fosas y desentierran los que encuentran allí, aún frescos, para comerlos entre cantos, bailes y grandes alegrías. Se trata, dicen, del manjar más exquisito que jamás comieron. Para poder celebrar y disfrutar mejor del banquete, los tahúres mandan a pedir a los hombres honrados de la hueste que les envíen pan y vino, y estos (entre ellos Boymonte, Godofredo de Bouillón, el conde de Flandes y el obispo de Puy) los complacen; el obispo de Puy incluso bendice, entre risas, a los tahúres y la carne que comen. Los moros se maravillan y espantan ante un comportamiento tan cruel, que consideran propio de gente maldita o bestias fieras. Atemorizado, el rey de Antioquía solicita una tregua.

Este episodio tan particular proviene de una vertiente textual en el seno de la tradición de relatos sobre las cruzadas. Dentro de esta vertiente, su reelaboración en la $G C U$ presenta una serie de rasgos distintivos.

\section{LOS ANTECEDENTES TEXTUALES}

Los primeros testimonios de antropofagia en las cruzadas se remontan a historias escritas por sobrevivientes de las primeras campañas: tanto Fulquerio de Chartres en su Historia Hierosolymitana como el autor anónimo de las Gesta Francorum et aliorum Hierosolimitanorum y Raimundo de Aguilers en la Historia Francorum qui ceperunt Iherusalem relatan cómo, en diciembre de 1098, durante el sitio de Maárat an-Numan o inmediatamente después, ya dentro de la ciudad, los cruzados asaron y devoraron cadáveres musulmanes, forzados por el hambre extrema. Relatos más tardíos, como la Chanson d'Antioche (un cantar de gesta francés de las últimas décadas del siglo XII, presuntamente basado en un poema anterior, perdido, compuesto por un juglar que habría estado presente en el sitio de Antioquía, y que dentro de su armazón épico ofrece detalles de notoria precisión histórica) o la Historia rerum in partibus transmarinis gestarum de Guillermo de Tiro, sitúan los incidentes de antropofagia unos meses antes, en junio de 1098, en el contexto del sitio de Antioquía. La recurrencia del suceso, a pesar de las vaguedades y las inconsistencias entre las diversas fuentes, así como el hecho significativo, por lo anómalo, de que en este caso la antropofagia no sea una acusación blandida para deshumanizar y desacreditar al enemigo (o, más ampliamente, al "otro") sino un comportamiento aberrante atribuido al bando dentro del cual se inscriben los autores, han llevado a los historiadores en general a reconocer cierta base de veracidad al acontecimiento, si bien oscurecida por la divergencia de las circunstancias provistas por los testimonios. ${ }^{3}$

Dentro de la serie de variaciones textuales desplegadas a partir del núcleo básico de la antropofagia de los cruzados, la reelaboración de Guiberto de Nogent de la Gesta Francorum, titulada Gesta Dei per Francos, introduce dos innovaciones ${ }^{4}$ que resultan relevantes para la configuración del episodio en la $G C U$. El abad se refiere a la presunta ingesta de cadáveres por parte de los cristianos en la sección XXII del Capítulo 5 del Libro Octavo (Migne, ed., 1853, cols. 811-813). En primer lugar, allí se narra cómo los propios cristianos alimentan los rumores sobre su supuesta antropofagia para infundir terror entre sus enemigos, al punto de montar la escena de un falso banquete como estrategia militar de amedrentamiento. Se trata, por otra parte, de unos rumores no desprovistos de algún sustento real, puesto que el relato de Guiberto deja entrever que en raras ocasiones, durante hambrunas severas, en Maárat y otros sitios, ciertos cristianos se habían alimentado de manera furtiva con tajadas de carne extraídas de cadáveres paganos. Más importante aún para la evolución posterior del episodio, esta antropofagia, real o fingida, se adscribe entre los turcos a un grupo específico dentro del colectivo de los cruzados: los tahúres (Thafures, en latín en el original). Por medio de esta diferenciación interna, la mácula de la antropofagia queda circunscrita a una categoría subalterna dentro del ejército cristiano, caracterizada además a través de un haz de rasgos que la vuelven un chivo expiatorio idóneo sobre el cual proyectar una conducta tan atroz (tal como señala Heng, 1998, pp. 114-116; ver también Rubenstein, 2008, pp. 539-540).

Guiberto presenta a este género especial de hombres dentro de la hueste cruzada como una multitud de indigentes que marcha, con los pies desnudos, mal vestidos y sin armas, por delante de las bestias de carga y el resto de los peregrinos. Afirma que su nombre, Thafures, significa vagabundos en lengua bárbara (sin 
mayores especificaciones, lo que en este contexto probablemente debe entenderse como árabe). ${ }^{5}$ Debido a su pobreza, se alimentan de hierbas, raíces y lo que encuentran en su camino. Obedecen a su rey, un caballero innominado de Normandía desprovisto de señorío, que había perdido su caballo y abandonado su ropa y sus armas para liderarlos. A pesar de ir desarmados, los tahúres son de gran utilidad para el ejército: transportan cargas y víveres y arrojan piedras y otros proyectiles a los enemigos durante los asedios. La pobreza extrema, la composición y el origen inciertos del colectivo, su anonimia indiferenciada, su marginalidad con respecto al núcleo de los cruzados, su relativa escisión de las normas generales, su afinidad con las bestias brutas (en virtud de su dieta, el lugar que ocupan en la marcha, su función y su aspecto miserable, al borde de la desnudez) los colocan en una situación liminal entre la cristiandad civilizada y el salvajismo animal. La suma de estos factores convierte a los tahúres en figuras expiatorias plausibles de encarnar, en el imaginario medieval, el fantasma de la antropofagia, liberando al común de los cruzados de esa culpa.

La Chanson d'Antioche es uno de los textos compilados y reelaborados por la $G C U$ y proporciona la fuente del episodio bajo consideración (Paris, 1888, p. 539; Northup, 1934; Domínguez, 2010), si bien la versión brindada por la crónica castellana presenta diferencias notables con el relato del poema francés tal como ha sido transmitido. ${ }^{6}$ En la Chanson, el episodio antropofágico se sitúa en las dos primeras secciones del canto quinto (Paris, ed., 1848, II, pp. 3-9). Ante los padecimientos del hambre y los rigores de un sitio prolongado, el rey tahúr acude a Pedro el Ermitaño en busca de consejo para que sus hombres no mueran a causa de la miseria. El clérigo achaca las congojas de los tahúres (Tafurs, en el original) a su desidia e indica una solución sencilla: tienen a su disposición abundancia de cadáveres turcos, que pueden cocinar y comer. Los tahúres siguen el consejo. Desuellan y vacían a los musulmanes muertos, cocinan su carne y la devoran con gusto a la vista de todos. Desde las murallas, los habitantes de Antioquía se espantan y lloran ante el espectáculo, considerándolo un acto de crueldad y una afrenta que degrada y deshumaniza a los franceses ("moult sont despersoné”, Paris, ed., 1848, II, p. 4) y los asimila a demonios. La noticia se expande rápidamente por la ciudad. El rey tahúr advierte la conmoción que están provocando entre los enemigos y resuelve conducir a sus ribaldos hasta el cementerio para desenterrar a los turcos ya sepultados, tras lo cual se disponen a faenar a los que hallan todavía frescos. Los líderes de la hueste cristiana acuden al sitio donde se reúnen los tahúres, no sin antes haberse armado (lo que delata un temor cierto ante la ferocidad exhibida por los ribaldos). Una vez allí, les preguntan entre risas cómo se encuentran; ante el desparpajo con el que los tahúres les responden, les envían vino con el que acompañar la comida. En una entrevista, el rey de Antioquía le reprocha a Boymonte que los cristianos sean capaces de tal villanía. Boymonte desliga a los líderes del ejército de cualquier responsabilidad y culpa enteramente a los tahúres, a quienes caracteriza como una clase de gente diabólica y por completo indomable, que actuó sin el consentimiento de los líderes de la cruzada y que ama la carne de turco mucho más que cualquier otra.

La antropofagia de los cristianos queda, una vez más, circunscrita a esta tropa de harapientos sin recursos. Ante la conducta de los tahúres, los caballeros cruzados reaccionan con ambigüedad, con una mezcla de risas y recelo por su propio bienestar. Sin embargo, frente al enemigo estos caballeros no vacilan en utilizar el episodio a su favor, aprovechándolo para propagar el terror y así conseguir una ventaja militar: en su audiencia con el rey de Antioquía, Boymonte destaca la avidez de los tahúres por la carne sarracena (que, según afirma, prefieren sobre el pavo) y exagera el carácter bravo e inmanejable de estos hombres, callando por otra parte que la antropofagia les fuera sugerida por Pedro el Ermitaño. Boymonte combina con habilidad verdad, omisión y mentira y a través de su discurso engalana e instrumenta el episodio en beneficio de la causa cruzada.

\section{El BANQUete de los tahúres en la Gran ConQuista DE ULtramar}

La versión que proporciona la $G C U$ del incidente antropofágico proviene de esta vertiente de la materia cruzada. También en la crónica castellana, el acto se circunscribe al grupo subalterno y diferenciado de los tahúres; sin embargo, el relato presenta una serie de variantes significativas con respecto a los dos reseñados. 
En primer lugar, el impulso antropofágico brota de manera espontánea dentro del colectivo de los tahúres, que amenazan con devorar a su rey (la máxima figura de autoridad que reconocen) si este no satisface de inmediato su apetito. De entrada, por lo tanto, esta multitud de pobres es caracterizada a través de la supremacía de los instintos más bajos del cuerpo por sobre cualquier posible consideración moral, política o religiosa, tales como el tabú de comer carne humana, la noción de pecado, la prohibición del asesinato, el respeto a la jerarquía, la atención a la disciplina; y, por eso mismo, como una muchedumbre al filo de la anarquía y el caos. La intervención de Pedro el Ermitaño no genera sino que encauza la pulsión antropofágica, reorientándola a un objeto más inocuo y aceptable, según los parámetros de la mentalidad medieval: cadáveres en vez de seres vivos, muertos ajenos a la comunidad de los ejércitos cristianos en vez de propios. De esta manera, el clérigo no provee a los tahúres de la inspiración para alimentarse de carne humana, como sí ocurre en la Chanson d'Antioche, donde es él quien propone la idea y los incita a llevarla a cabo. En la $G C U$, el discurso de Pedro el Ermitaño redirecciona un impulso previo y al hacerlo lo torna menos criminal, pecaminoso, aberrante y dañino y, por añadidura, funcional a los intereses de los cruzados: por un lado, porque al garantizar la satisfacción de las necesidades urgentes de la gente menuda, se aplacan los peligros de la deserción y la sublevación, tan temidos por los líderes del ejército; y, por otro, porque la conducta de los tahúres servirá para desmoralizar a los enemigos, como anticipa el propio Pedro. Deben reconocerse, asimismo, el pragmatismo y la eficacia de la solución propuesta por el clérigo: ni los despojos del rey tahúr ni los del asno habrían bastado para saciar el apetito de miles de pobres, mientras que el tendal de cadáveres enemigos sembrado por la guerra, sí. La segunda particularidad del relato castellano es el relieve que proporciona a la arenga con la que Pedro el Ermitaño anima a los tahúres a alimentarse de la carne de los moros muertos, y al poder de persuasión que enseguida ejercen sus palabras. Esto se corresponde con la eficacia y la importancia crucial que se les reconoce, a lo largo de la $G C U$, a las prédicas de los clérigos en el impulso y el posterior desenvolvimiento de la campaña cruzada, en cuanto herramientas motivacionales y disciplinarias poderosas.

Otro de los rasgos notables del tratamiento del episodio en la $G C U$ es el mayor despliegue de la dimensión sensual y gozosa que reviste el festín de los tahúres. Esto se plasma en la prodigalidad de detalles acerca de las distintas maneras en que los tahúres adoban y cuecen los cadáveres, la insistencia en cuán sabrosos les resultan, el entusiasmo con el que se dedican a los preparativos y la ingesta, los festejos con que rodean el banquete. La alegría de los bellacos es contagiosa y se transmite a los líderes del ejército cruzado, que ríen con ellos (aunque no debe descartarse que, al menos en parte, también sea de ellos, de la atrocidad de los placeres a los que salvaje y felizmente se entregan: nunca se desdibujan la superioridad jerárquica y la distancia diferenciadora entre un grupo y el otro) y contribuyen al disfrute y las celebraciones de sus subalternos regalándoles pan y vino de sus propias provisiones. La risa se generaliza y parece diluir, por un rato, el carácter terrible, repulsivo e impuro que usualmente posee en el imaginario cristiano medieval la acción de alimentarse de cadáveres humanos. ${ }^{7}$

El humor grotesco, así como la hipérbole del carácter deleitoso del banquete, transforman radicalmente el acto del consumo forzado, vergonzante y penoso de cadáveres humanos (que se supone se encuentra en la base de todos estos relatos) en otra cosa. Ya no se trata de "canibalismo de supervivencia", una práctica normalmente prohibida a la que se recurre en condiciones críticas, sino de un exponente jocoso de "canibalismo gastronómico", en el que la carne humana es consumida y valorada por su sabor y las sutilezas de su preparación (según una de las varias tipologías posibles del fenómeno, en este caso según el motivo que impulse a la antropofagia - ver Arens, 1979, p. 18-). Incluso se celebra el suceso con una fiesta.

La alegría de los tahúres, se señaló antes, se extiende en la risa del obispo de Puy, y ambas potencian la comicidad del episodio tal como aparece presentado ante el lector. Harriet Goldberg, al examinar el tema del canibalismo en la narrativa ibérica, observa que se trata del único tabú que ha generado una vertiente reconocible dentro del humor popular, y que es probable que en este tipo de relatos la risa tenga un propósito liberador y sirva para aliviar el malestar suscitado por la experiencia de pensar lo impensable (1997, p. 107). ${ }^{8}$ No sería descabellado asumir que la risa del obispo de Puy encubre una comprensible incomodidad; así como es indudable, por otra parte, que los recursos que despliega el relato para infundir comicidad al episodio 
se orientan a atenuar una incomodidad semejante en el receptor, distrayéndolo del horror inherente a los hechos evocados. La risa del obispo y las bendiciones que imparte median entre el lector y la atrocidad de los cadáveres ultrajados a causa del hambre, y son dos de los recursos que contribuyen a mitigar el espanto. Al santiguar el banquete con el peso de su autoridad religiosa, el obispo de Puy lo absuelve de juicios y condenas ulteriores (tal como había hecho antes Pedro el Ermitaño: es significativo que uno y otro gesto enmarquen el festín); con su risa, proferida en calidad de observador externo al convite, incita al lector (observador externo en segundo grado) a reírse desprejuiciadamente a su vez.

Los únicos excluidos de esta risa diegética y extradiegética son los musulmanes. Paradójicamente, en el relato son los moros quienes frente a la antropofagia expresan los reparos que cabría esperar de los pueblos civilizados, de acuerdo con la cosmovisión jerarquizada del occidente medieval: se espantan, lloran, hacen grandes duelos, condenan el comportamiento por considerarlo cruel, impío, propio de gente maldita o animales salvajes, tienen miedo. Tal como señala Goldberg, "High moral ground is held by the Moorish King of Antioch" (1997, p. 120), quien en este sentido contrasta de manera absoluta con sus contrapartes cristianas. En el "otro" por antonomasia, el enemigo inspirado por el diablo a quien se pretende expurgar de las tierras santas, se proyectan los valores habitualmente tenidos por propios, mientras que es el colectivo cruzado quien adopta y tolera entre sus filas el canibalismo.

Esta especularización sorprendente de los valores y los prejuicios comúnmente aceptados es otro de los rasgos que singularizan el episodio. Esta particularidad resulta más notable aún cuando se la considera en relación con la concepción del mundo plasmada en enciclopedias, relatos de viajes y mapamundis europeos medievales, caracterizada por un marcado etnocentrismo y organizada en torno a la oposición de un centro civilizado y márgenes monstruosos. ${ }^{9}$ En los siglos medievales, así como antes en el mundo clásico grecolatino, la monstruosidad no se define únicamente por las anomalías físicas; los hábitos diferentes de los propios de la cultura del observador a menudo alcanzan para establecer la exclusión del género humano, o cuanto menos una inquietante liminaridad. En tratados, enciclopedias y relatos, la alimentación de los pueblos es uno de los factores más importantes y recurrentes al describir a las razas monstruosas, y

l'antropofagia rappresenta il grande motivo di discriminazione fra l'umanità degna di questo nome e il mondo delle fiere [.] Per [gli Europei] il cannibalismo è a priori un vizio mostruoso, lo dimostra il fatto che gli antropofagi siano annoverati tra i mostri fin dall'antichità (Sebenico, 2005, p. 126).

Ya se señaló antes cómo la vestimenta, la suma pobreza, los hábitos alimenticios, la carencia de armas, la organización interna, la ubicación y el rol de los tahúres dentro del ejército cruzado los sitúan en una posición literal y simbólicamente periférica, colindante con las bestias. La entrega gustosa a la antropofagia ratifica y extrema esta marginalidad, poniendo en evidencia que la propia cristiandad cruzada comprende en sí misma, como un microcosmos, un centro ideal -el modelo caballeresco fugazmente encarnado por Godofredo de Bouillón - y márgenes no tan virtuosos, comportamientos ejemplares y conductas aberrantes, a menudo confusa e inestablemente mezclados. Incluso Godofredo de Bouillón, cima de virtud, regala con vino y provisiones el festín de los tahúres, y más adelante les cabrán a estos los honores de ingresar primeros en la ciudad santa de Jerusalén, así como de que su rey sea señalado por el conjunto de los hombres honrados como "el más alto hombre de toda aquella cavallería e compañía" (II, p. 499) y, por lo tanto, el más digno de coronar a Godofredo rey. La mirada externa de los musulmanes de Antioquía contempla este desorden de las huestes cristianas desde el espacio organizado y contenido por las murallas todavía invioladas de la ciudad y lo refleja con espanto. ${ }^{10}$

La respuesta que Boymonte brinda al rey Harsilis en la $G C U$ presenta asimismo sus puntos de interés. $\mathrm{Al}$ igual que en la Chanson d'Antioche, Boymonte exime a los hombres honrados de la hueste de cualquier vinculación con las atrocidades antropofágicas ("que esto no lo hazían ellos, ni era por su consejo" —-II, p. 41 -), ya que los arlotes obedecen únicamente a su rey, y pondera la afición que los tahúres han tomado por la 
carne de los moros, “que dezían que nunca comieran cosa que les assí supiesse” (II, p. 41). Pero en la crónica castellana, Boymonte añade algo más:

que todos ellos [los arlotes] vinieran por salvar sus almas, assí como todos los otros que eran en la hueste; e que tan gran voluntad havían de las salvar, que no tan solamente matavan los moros, mas comíanlos, después que los havían muerto, por doquier que los hallar podían, tan bien los que yazían soterrados como los otros que hallavan de fuera (II, p. 41).

Convierte así el que originariamente fuera un acto desesperado para asegurar la supervivencia, transmutado luego en un festín, en la manifestación de un celo religioso extremo. En su argumentación, la antropofagia deja de ser una conducta reconocida como impura y pecaminosa para tornarse una vía de salvación de las almas por estar dirigida contra los enemigos de la fe. La narración no da indicios de si se trata meramente de una pirueta retórica o de una convicción genuina por parte del príncipe. En cualquiera de los dos casos, tal como sucedía en el cantar de gesta francés, las palabras de Boymonte tienen el efecto de incrementar el miedo del rey. $\mathrm{Y}$ añaden un nuevo avatar a las transformaciones que atraviesa el episodio, desde sus primeros testimonios en adelante y también dentro del propio relato de la $G C U$ : lo rescatan de la esfera de lo monstruoso y lo aberrante, así como de la del mero disfrute sensual y jocoso, para inscribirlo en la lógica de la peregrinación, un camino de asperezas y dificultades emprendido con el propósito de purgar los pecados y salvar el alma, que es, como se señaló en los párrafos iniciales, uno de los ideologemas fundamentales en los que se sustenta el discurso de las cruzadas. Dentro de esta lógica, el banquete de los tahúres se concibe, finalmente, como un acto de purificación y limpieza, de sí mismos y del mundo.

\section{LOS SENDEROS DE LA FICCIÓN}

Los testimonios parecen indicar que, en el seno de la cultura medieval, los actos antropofágicos por parte de los cruzados fueron asumidos, y por lo tanto experimentados, como reales. ¿Cómo aceptar y entender una aberración semejante? ¿Cómo relatar un suceso tan horrendo que se sitúa al filo de lo inconcebible? ¿Cómo integrarlo en una narración coherente y comprensiva, que lo dote de sentido? ¿A través de qué procedimientos y negociaciones pueden la memoria cultural y el imaginario colectivo lidiar con una atrocidad así? Geraldine Heng ha propuesto que de estas exigencias y presiones surge el romance medieval, como una modalidad narrativa definida por una particular articulación de fantasía e historia que permite transformar el trauma cultural y proporciona un lenguaje seguro para hacerlo (Heng, 1998, especialmente pp. 101, 102, $106,107) .{ }^{11}$

Los apartados previos han procurado poner de relieve una serie de cuestiones. En primer lugar, se ha esbozado un recorrido a través de las formas en que sucesivas representaciones del episodio antropofágico lo han configurado a lo largo de una de las vertientes de la tradición historiográfica y épica sobre las cruzadas, y cómo este episodio en consecuencia se ha ido transformando progresivamente, hasta arribar a la reelaboración ofrecida por la $G C U$. Como culminación de este recorrido, se ha destacado una serie de rasgos y procedimientos que se conjugan en la versión castellana del episodio: la particularización de la culpa, a través de la atribución de la falta a un colectivo de contornos oscuros, subalterno y marginal dentro del ejército cruzado, los tahúres; la comicidad grotesca que reviste el episodio entero, en la que confluyen la exacerbación del goce del banquete, el desarrollo de los preparativos, la multiplicación de las risas; la bendición del festín por los clérigos; su justificación religiosa a través de la inscripción en la lógica del peregrinaje; el realce y el aprovechamiento de sus efectos desmoralizadores en el enemigo. Aquí también se articulan la memoria histórica y las mecánicas de la ficcionalización, con el efecto de atenuar el horror inherente a los sucesos evocados e iluminar su significado. Es sabido que los cronistas medievales escogen, combinan, manipulan y reescriben sus materiales de acuerdo con la interpretación o la concepción de la verdad que pretenden plasmar; en la $G C U$, esta tendencia se extrema y adquiere una nueva impronta por el modo y la relevancia con que se integran en el entramado textual las canciones de gesta, que disuelven el rigor de la historia en 
un ámbito de relaciones fantásticas y nuevos significados, según observa Fernando Gómez Redondo (1998, p. 1039).

Se ha reconocido a la $G C U$ un rol relevante en el proceso de emergencia de la prosa de ficción en lengua vernácula por ser "la vía por la que [ingresan] en la literatura castellana nuevos procedimientos de pensar la realidad", propios de la ficción (Gómez Redondo, 1998, p. 1029), así como materiales narrativos caballerescos, folclóricos, épicos y de otras índoles, que anticipan o abonan las líneas fundamentales por las que se desenvolverá la narrativa en prosa de comienzos del siglo XIV. En lo que respecta al episodio bajo consideración, es muy probable, tal como señala Cristina González (2002), que el relato del banquete de los tahúres haya influido en la particular reelaboración del cuento del medio amigo que ofrece el Libro del Cavallero Zifar (González, ed., 1983, pp. 81-85). Entre las versiones medievales en castellano de este cuento, la del Zifar se diferencia de las demás y de su común antecedente latino ${ }^{12}$ por la inclusión del tema de la antropofagia (Zubillaga, 2010, pp. 275-276) y por el humor con que se lo aborda, un elemento por completo ausente, además, de las otras variantes castellanas y que tanto Kenneth Scholberg (1958) como González (2002) coinciden en destacar como la característica central y distintiva del cuento engarzado en el Zifar. El humor es asimismo, como pudo observarse, la nota dominante en el episodio del festín de los arlotes de la $G C U$. La ligazón entre comicidad y antropofagia, así como la fruición con que el mozo del cuento devora la que cree ser la carne de su enemigo, son coincidencias llamativas entre ambos relatos, que bien podrían ser indicios de que el autor del Zifar tenía presente el recuerdo de la $G C U$ al momento de escribir este enxemplo.

La inclusión del cuento ejemplar del Zifar como un nuevo eslabón en la cadena de reelaboraciones del tema antropofágico desplegadas a partir de los acontecimientos de las cruzadas permite situar la $G C U$ en un proceso de transformaciones textuales vasto y significativo. Del latín a las sucesivas lenguas romances; de los testimonios compuestos al calor de los hechos a las variaciones progresivamente más audaces; de la incertidumbre de las circunstancias a un desarrollo narrativo cada vez más fino y cabal; del tabú a la paulatina elaboración del horror y luego la risa; de la oscuridad de los sucesos al discurso histórico, sometido a los imperativos de la narración, las reescrituras y los efectos acumulativos de la ficcionalización, y, por último, la recreación libre en el ámbito ficcional del cuento y el romance de aventuras.

\section{REFERENCIAS}

Arens, W. (1979). The Man-Eating Myth: Anthropology \& Anthropophagy. New York: Oxford University Press.

Cooper, L. (Ed.). (1979). La gran conquista de Ultramar (4 Vols.). Bogotá: Instituto Caro y Cuervo.

Domínguez, C. (2010). Gran conquista de Ultramar. En G. Dunphy (Ed.), Encyclopedia of the Medieval Chronicle (pp. 726-727). Leiden y Boston: Brill.

Godefroy, F. (1892). Dictionnaire de l'ancienne langue française et de tous ses dialectes du IXe au XVe siècle. Tome VII. Paris: F. Vieweg.

Goldberg, H. (1997). Cannibalism in Iberian Narrative: The Dark Side of Gastronomy. Bulletin of Hispanic Studies, 74(1), 107-122. https://doi.org/10.1080/000749097760143553

Gómez Redondo, F. (1998). Historia de la prosa medieval castellana, vol. I. La creación del discurso prosístico: el entramado cortesano. Madrid: Cátedra.

González, C. (Ed.). (1983). Libro del caballero Zifar. Madrid: Cátedra.

González, C. (1992). La tercera crónica de Alfonso X: La gran conquista de Ultramar. London: Tamesis Books.

González, C. (2002). El cuento del medio amigo y la articulación onírica del Zifar. Revista de Literatura Medieval, 14(1), 53-62. Recuperado de: http://hdl.handle.net/10017/5417

Heng, G. (1998). Cannibalism, the First Crusade, and the Genesis of Medieval Romance. Differences: A Journal of Feminist Cultural Studies, 10(1), 98-174.

Migne, J.-P. (Ed.). (1853). Venerabilis Guiberti abbatis S. Mariae de Novigento opera omnia. Paris: Migne. 
Northup, G. T. (1934). La Gran Conquista de Ultramar and its Problems. Hispanic Review, 2, 287-302.

Paris, P. (Ed.). (1848). La Chanson d'Antioche. (2 vols.). Paris: J. Techener.

Paris, G. (1888). La Chanson d'Antioche provençale et la Gran Conquista de Ultramar. Romania, XVII, 513-541. ht tps://doi.org/10.3406/roma.1888.6029

Porges, W. (1946). The Clergy, the Poor, and the Non-combatants on the First Crusade. Speculum, 21(1), 1-23. htt ps://doi.org/10.2307/2856833

Rubenstein, J. (2008). Cannibals and Crusaders. French Historical Studies, 31(4), 525-552. https://doi.org/10.1215 /00161071-2008-005

Scholberg, K. (1958). A Half-Friend and a Friend and a Half. Bulletin of Hispanic Studies, 35(4), 187-198. https://d oi.org/10.1080/1475382582000335187

Sebenico, S. (2005). I mostri dell'Occidente medievale: Fonti e diffusione di razze umane mostruose, ibridi ed animali fantastici. Trieste: Università di Trieste.

Sumberg, L. (1959). The Tafurs and the First Crusade. Mediaeval Studies, 21, 224-246. https://doi.org/10.1484/J. MS.2.306650

Zubillaga, C. (2010). La antropofagia y las dinámicas de la enseñanza en dos romances caballerescos del Siglo XIV: el Libro del cavallero Zifar y la Estoria del Rey Guillelme. Revista de Literatura Medieval, 22, 271-282. Recuperado de http://hdl.handle.net/10017/10457

\section{Notas}

1 Sobre esta dualidad, la importancia de la tradición del peregrinaje en las prédicas de Urbano II y sus consecuencias en la conformación de la expedición cruzada, ver Porges (1946).

2 Todas las citas del texto estarán tomadas de esta edición, por lo que en lo subsiguiente me limito a indicar los números de tomo y página.

3 Para un balance de los diversos testimonios medievales sobre la antropofagia de los cruzados, diferentes valoraciones de historiadores modernos y un ensayo de interpretación de conjunto, ver Rubenstein (2008). Heng, desde una perspectiva complementaria, repasa distintos relatos medievales al respecto y concluye que, al margen de la imprecisión y la variabilidad de las circunstancias, la antropofagia de los cruzados es un hecho irreductible y sin dudas experimentado como real en el seno de la cultura medieval (1998, especialmente pp. 102-106 y sigs.).

4 No puede descartarse que Guiberto tomara parte de su material de la versión original de la Chanson d'Antioche (como sugiere, por ejemplo, Porges, 1946, p. 12), pero los contenidos y la propia existencia de esa versión primigenia, supuestamente perdida, son para nosotros conjeturales. La antelación de uno u otro relato, así como la discusión acerca de la historicidad de los tahúres, exceden los objetivos y la perspectiva de este artículo. En mi exposición me refiero en primer lugar a la Gesta Dei per Francos simplemente por ser un texto anterior a la versión conservada de la Chanson d'Antioche tal como la conocemos, y por presentar esta última un relato del episodio en cuestión más desarrollado que la Gesta y más próximo al de la GCU. En cuanto al debate sobre la historicidad o el carácter ficcional de los tahúres, me limito a considerar la funcionalidad narrativa que va adoptando en los diferentes testimonios este personaje colectivo, de contornos difusos y sin duda trabajados por la leyenda, al margen del interrogante sobre su existencia fáctica.

5 "Inde rex Thafur barbarica coepit lingua vocari. Thafur autem apud gentiles dicuntur, quos nos, ut nimis litteraliter loquar, trudenues [al., trudennes, Gallice truands,] vocamus. Qui ex eo sic appellantur quia trudunt, id est leviter transigunt, quaqua versum peragrantes annos" (Migne, ed., 1853, col. 811; los corchetes corresponden al editor). Es muy posible que la palabra provenga del árabe takfür y este, a su vez, del armenio tahavor (rey); sin embargo, el origen del uso y el significado primario de la palabra entre los cruzados son oscuros. En francés medieval el término adquiere, por extensión, los significados de vagabundo, mendigo, truhan, bribón, y se aplica, según las fuentes, a colectivos sarracenos o cristianos (Godefroy, 1892, VII, p. 623). La GCU ofrece testimonio de las connotaciones corrientes del término al denominar alternativamente a los tahúres arlotes y vellacos; algo similar ocurre en la Chanson d'Antioche, que los llama ribaus (ribaldos). Sobre etimologías posibles e hipótesis acerca de los alcances primarios del término y la composición étnica del colectivo así designado, ver Porges, 1946, p. 12; Sumberg, 1959, pp. 226-230; Heng, 1998, pp. 152-153, aunque se trata en todos los casos de conjeturas no concluyentes.

6 Paris (1888, p. 539) sugiere la posibilidad de que la crónica castellana recoja una versión menos antigua del episodio que la conservada en el poema francés. En efecto, el cotejo pone en evidencia que el relato castellano presenta ciertos pormenores ausentes del cantar de gesta, lo que muy probablemente indica un estadio ulterior en el desarrollo narrativo 
del episodio. No puede saberse en qué medida estos cambios y amplificaciones corresponden al traductor o al compilador castellano o si ya estarían presentes en el texto francés empleado.

7 El asunto es vasto. Solo a modo de referencia, remito a las consideraciones generales planteadas en Heng, 1998, pp. 106-110.

8 Goldberg prácticamente no se detiene en el episodio de los tahúres en la $G C U$, al que solo se refiere al pasar y como término de contraposición con la hostilidad inherente al acto caníbal de los habitantes de la ciudad sitiada en El cerco de Numancia, de Miguel de Cervantes. Para la autora, el de los tahúres es un caso de "simple survival cannibalism", si bien notable por llevarse a cabo "with the indulgent approval of Peter the Hermit, their officers and the Bishop of Puy” (Goldberg, 1997, p. 120). Como se desprende de lo expuesto en el análisis, convendría matizar ambas apreciaciones: ni el relato presenta el accionar de los arlotes como un simple acto forzoso de supervivencia, ni el rol de los líderes religiosos y militares del ejército cristiano, comenzando por Pedro el Ermitaño, se limita a la aprobación indulgente.

9 Para profundizar en el etnocentrismo medieval, sus fuentes y sus concepciones acerca de la humanidad monstruosa y la organización del mundo, ver Sebenico, 2005, especialmente pp. 109-156.

10 González considera que "La Conquista presenta las cruzadas como una empresa en la que los cristianos van a afirmar su bondad frente a la maldad de los moros y a eliminar la ambigüedad moral del mundo” (1992, p. 98), e identifica la preocupación por esta ambigüedad y la lucha contra ella como uno de los ejes fundamentales del relato. En esta línea, plantea una triple oposición entre civilización (representada por los buenos cristianos), salvajismo (la ausencia de ley de los malos cristianos) y barbarie (la ley otra de los moros, situada por fuera de la civilización), y desde esta perspectiva analiza el episodio del banquete antropofágico, proponiendo que la función de los tahúres en la obra es encarnar el salvajismo que los propios cristianos no pueden controlar dentro de sí mismos y que eventualmente se presentará como la causa del fracaso de la expedición (desarrollado en González, 1992, pp. 99-101).

11 Heng centra su atención en la Historia Regum Britanniae de Geoffrey de Monmouth y el modo en que, a su juicio, lidia con el trauma cultural de la antropofagia de los cruzados.

12 El cuento del medio amigo se difundió en el occidente europeo a través de la Disciplina clericalis de Pedro Alfonso; su fuente es desconocida. Scholberg (1958) examina las diferencias entre las principales versiones castellanas. 